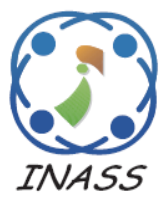

\title{
Kalman Observer Contribution to a Second Order Sliding Mode Control for Wind Turbine Based on DFIG During the Network Voltage Dip
}

\author{
Azeddine Loulijat ${ }^{1 *}$ \\ Najib Ababssi ${ }^{1}$ \\ Makhad Mohamed ${ }^{2}$ \\ ${ }^{1}$ Laboratory of Engineering Industrial Management and Innovation, Faculty of Science and Technique, \\ Hassan I University, Settat, Morocco \\ ${ }^{2}$ Laboratory of Electrical Engineering Robotics and Automation Research Team, \\ High Normal School of Technical Education, Mohammed V University, Rabat, Morocco \\ *Corresponding author's Email: rehalloulijat@gmail.com
}

\begin{abstract}
The main problem of the Doubly-Fed Induction Generator (DFIG) is its sensitivity to network disturbances especially voltage dip due to its stator windings being directly linked to the network. A voltage dip in the network results from high current peaks in the stator windings, since the stator and rotor are electromagnetically coupled, so these peaks provoke inrush current hard at the delicate back-to-back converters and an overcharge of the DC-LINK capacitor. In this perspective, several researchers are realized a linear and nonlinear controller with a passive protection method (PPM). The objective of this paper is to develop modelling and control models based on a true DFIG model considering the effect of all the parameters of a stator winding. The Second- Order Sliding Mode controller (SOSMC) is the non-linear control strategy used to control the dynamics of the DFIG through the rotor-side and network-side power converters under normal network conditions. When a voltage dip is detected, the Kalman observer (KO) contributes to a non-linear controller and the latter is coupled to a passive protection method that contains crowbar and DC-chopper circuits to improve the dynamics of the DFIG system to cross the network fault. Also, a comparative study is carried out between the developed controller and other linear, non-linear approaches exist in the literature. The results obtained, under a maximum voltage dip (100\%) on the $60 \mathrm{kV}$ network, confirm its robustness and superiority in terms of limiting the DFIG graders at the beginning and on termination of a fault. In terms of Ir and Vdc values during a voltage dip, our control strategy does not exceed 1.45p.u and 1.2p.u, on the contrary, the ABC with HGO which is developed recently reaches 2.2 p.u and 0.4 p.u.
\end{abstract}

Keywords: Crowbar, DC-Chopper, (DFIG), Kalman observer (KO), Network voltage dip fault , Passive protection method (PPM), Second-order sliding mode controller (SOSMC).

\section{Introduction}

The world electricity production is rapidly changing towards renewable energies: photovoltaics, wind, biomass, hydropower, tides, due to the negative effects of fossil fuels on the natural environment. Renewable energy produced from the wind by a wind turbine is the most cost-effective due to its all-day availability $[1,2]$.

Wind turbines used in all wind farms, based on the doubly fed induction generator (DFIG) technology are practically the most commonly used [3]. Compared to wind turbines using fixed-speed asynchronous generators, DFIG-based wind turbines provide three main advantages. First, the rotor converters can be rated to support only $25-30 \%$ of the total nominal power of the generator, thereby reducing the cost. Second, its capacity to provide variable speed operation means that energy can always be extracted even at low wind speeds and that DFIG rotates at the optimal rotational speed for each wind speed, which minimizes mechanical stress, improves energy quality, and compensates for torque and power pulsations. Finally, the rotor-side converter (RSC) can be controlled to place the turbine system at an operating point where energy extraction is maximal through a technique called 
'Maximum Power Point Tracking (MPPT)' [4-7]. There are several approaches to the transformation of DFIG in the literature to successfully achieve control of the wind system, we find like Stator Voltage Orientation (SVO) [8] and Stator Flux Orientation (SFO) [9], in many cases, these approaches have been successfully combined with linear and non-linear controls like proportionalintegral controller (PIC) [10, 11],Classic Sliding Mode Controller (CSMC) [11] and Adaptadtive Backstepping controller(ABC) [12] with High Gain Observer (HGO) [13] to control the DFIG effectively but under stable network conditions. However, most wind farms are located in remote or rural areas. The electricity network in these areas is characterized by different disturbances in the form of voltage dips. In the DFIG configuration, the stator side is directly connected to the network, which makes the DFIG sensitive to network disturbances and the occurrence of network fault such as voltage dip leads to stator current increasing, pulsations in stator active and reactive power and electromagnetic torque $[14,15]$. In addition, due to the magnetic coupling between the stator and the rotor, this increase in stator current also flows through the rotor circuit and the electronic power converter; this can lead to destroying the converter and the Power control of the DFIG is lost even after the fault is cleared. The innovative strategy to avoid the destruction of the converter during network fault was to disconnect the DFIG from the network. Because of the massive introduction of the wind turbine into the electricity network today, this practice compromises the recovery of the network voltage. Network operators have therefore developed strict during network fault and, in some cases, provide network codes that require wind turbines to remain connected reactive energy to the network to facilitate its voltage recovery. Therefore, it is necessary to integrate strategies in the wind system to remain connected to the network during the fault, and therefore to cross the fault. Therefore, it is necessary to integrate strategies in the wind system to remain connected to the network during the fault, and therefore to cross the fault . To help DFIG tolerate network faults, many techniques have been proposed in the literature, which can be classified into three groups: (1) integration of additional protection device [16], (2) installation of reactive power supplying devices like STATCOM and DVR [17], and (3) use of advanced control approach [18]. The most commonly used protection devices are resistors crowbar and DCchopper. A crowbar is a three-phase resistor coupled in parallel with the winding of the rotor via the IGBT switches. During a fault, the IGBT switches are closed and the three-phase resistors connected to the rotor to limit the current and therefore the protection of the rotor-side converter, and the DC-chopper device is a braking resistor whose role is to limit the overvoltage at the DC-LINK terminals, thus protecting the connection capacitor [19] . These techniques are often combined with a PI type linear control.

When the electrical network is subjected to a fault in the form of a voltage dip, the behaviour of the DFIG becomes non-linear, this justifies that the PI linear control cannot efficiently handle the current peaks at the instant of fault occurrence and fault clearance [1] . To remedy this problem a nonlinear control is necessary, we find CSMC is a nonlinear control technique derived from variable structure control system theory used in [11] is robust but its performance is marred by high frequency low oscillations called chattering. An advanced version of the CSMC is the SOSMC using the super-twisting algorithm for its design, which has been proven in [6, $20]$ to be robust against internal disturbances such as parameter variations and system uncertainties.

In our work, unlike previous work on DFIG, where researchers always neglect stator resistance to facilitate its control, this resistance was taken into account in the study so that the studied system is close to reality. In this paper, the SOSMC is tested in terms of external perturbations in the form of a voltage dip in the network. The second-order sliding mode controller is constructed to control the stator's active and reactive power through the RSC. The DCLINK voltage and the reactive power of the filter are controlled using the second-order sliding mode controller through the NSC. A KO is designed to estimate the power generated on the rotor side of the DFIG, the power losses in the RSC, NSC converters, and the DC-LINK capacitor to make the control strategy more efficient and without the influence of the measurement noise introduced by the sensors. The SOSMC is combined with a PPM containing the crowbar and DC-chopper to improve the DFIG's ability to penetrate the network fault. After correctly selecting the controller parameters to ensure optimum performance, the controller is first examined without activation of the PPM under a voltage dip in the network.

Secondly, the capability of the DFIG is improved by adding the activation of the PPM to the SOSMC as shown in fig. 1 so that the global system passes the network fault. In the results of the simulations performed, the SOSMC with PPM is analyzed and compared with the existing strategies in the literature [10-13] and shows that the first strategy has a better performance of the dynamics and robustness 


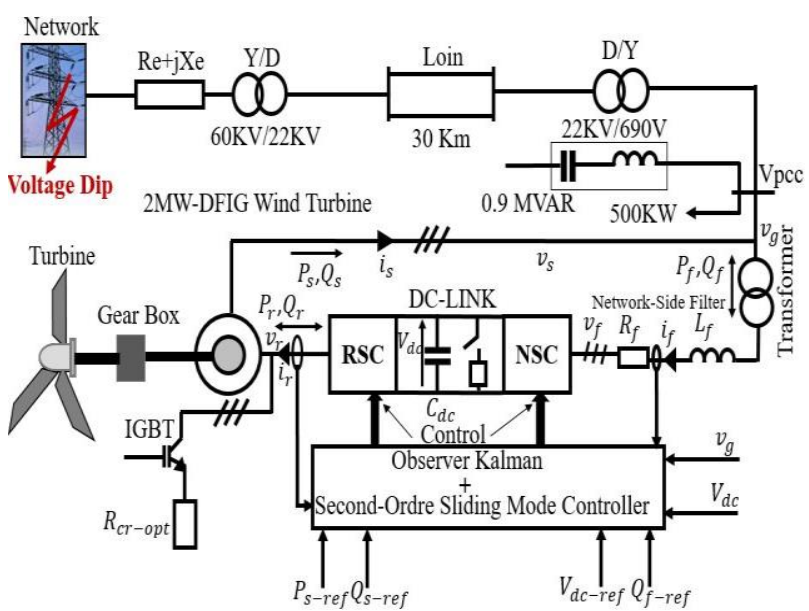

Figure. 1 An overall diagram of a wind power system connected to the electricity network

of the DFIG during a voltage dip at the limitation of the parameters influenced by this fault.The next sections of the paper is organized as shown below. In section 2, we start with the definition and representation of the different zones of the specific network code in which the wind power system is connected. Section 3 deals with the description and equations of the system. In section 4, the SOSMC strategy and the $\mathrm{KO}$ are represented, synthesized and applied on the wind system. The results of the MATLAB/Simulink simulation using a DFIG-2MW wind turbine with the addition of the PPM components are presented in the last section; these results are compared and discussed with the existing strategies in the literature [10, 11-13].

\section{Specific network code}

Wind farms are kept connected and sustain the network during and after a fault by following a required network code. The network code to be respected in this paper is given in Fig. 1. Zone 1 indicates the region where there is no tripping and the wind farm remains connected to the network, even the voltage of the common network coupling point has dropped to zero. Zone 2 indicates the tripping of the wind farm.

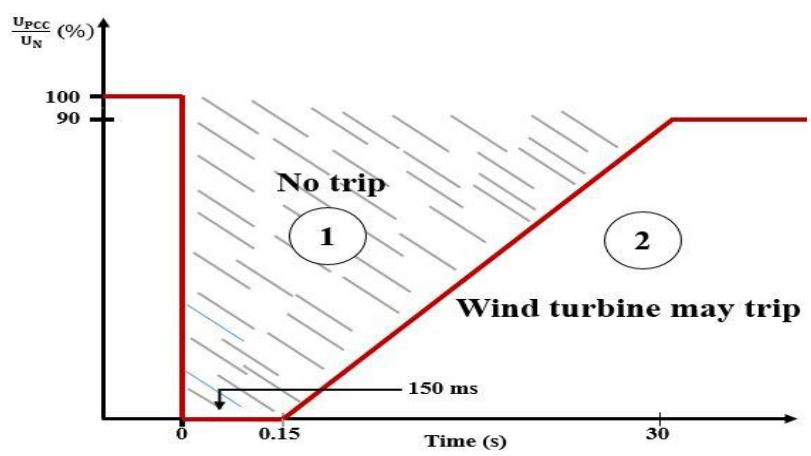

Figure. 2 Voltage dip requirement

\section{Description and equations of the system}

\subsection{System description}

Fig.1. Shows the overall schematic of the proposed electrical installation of a wind system connected to the electrical network. It is divided into two parts: the first mechanical part contains wind turbine, gearbox, and the second electrical part contains DFIG, electrical converters, DC-LINK, and grid side filter. For the electrical part, DFIG is connected to the utility network directly via its stator and indirectly through its rotor with the intermediary of converters, DC-LINK, and grid side filter.

\subsection{Rotor-side converter equations}

The asynchronous rotating $\mathrm{d}-\mathrm{q}$ reference frame is used to model the DFIG with the direct -axis oriented along the stator flux position is given in Eqs. (1) to (5). In this direction, the decoupled control of the active and reactive powers of the stator is attained. The reference frame is rotating with angular $\operatorname{speed} \omega_{s}$. The voltages equations are:

$$
\begin{aligned}
& v_{d s}=R_{s} i_{d s}+\dot{\varphi}_{d s}-\omega_{s} \varphi_{q s} \\
& v_{q s}=R_{s} i_{q s}+\dot{\varphi}_{q s}+\omega_{s} \varphi_{d s} \\
& v_{d r}=R_{r} i_{d r}+\dot{\varphi}_{d r}-\omega_{r} \varphi_{q r} \\
& v_{q r}=R_{r} i_{q r}+\dot{\varphi}_{q r}+\omega_{r} \varphi_{d r}
\end{aligned}
$$

Where slip speed $\omega_{r}$ is the difference between stator angular speed $\omega_{s}$ and the product of the number of pairs of poles $p$ and rotor speed $\Omega_{m}$ as indicated in Eq. (5):

$$
\omega_{r}=\omega_{s}-p \Omega_{m}
$$

The flux equations are:

$$
\begin{aligned}
& \varphi_{d s}=L_{s} i_{d s}+M i_{d r} \\
& \varphi_{q s}=L_{s} i_{q s}+M i_{q r} \\
& \varphi_{d r}=L_{r} i_{d r}+M i_{d s} \\
& \varphi_{q r}=L_{r} i_{q r}+M i_{q s}
\end{aligned}
$$

The instantaneous expressions of the different powers involved in the new d-q frame are: 


$$
\begin{aligned}
& P_{s}=1.5\left(v_{d s} i_{d s}+v_{q s} i_{q s}\right) \\
& Q_{s}=1.5\left(v_{q s} i_{d s}-v_{d s} i_{q s}\right) \\
& P_{r}=1.5\left(v_{d r} i_{d r}+v_{q r} i_{q r}\right) \\
& Q_{r}=1.5\left(v_{q r} i_{d r}-v_{d r} i_{q r}\right)
\end{aligned}
$$

The electromagnetic torque equation is given by:

$$
T_{e m}=1.5 p \frac{M}{L_{s}}\left(\varphi_{q s} i_{d r}-\varphi_{d s} i_{q r}\right)
$$

The orientation of the stator flux vector along the $\mathrm{d}$-axis is to help control the electrical output of the wind power system. This orientation will be done with a real DFIG model; taking into consideration the stator resistance.

$$
\varphi_{d s}=\varphi_{s} \varphi_{q s}=0
$$

And the stator voltages are reduced to:

$$
\begin{gathered}
v_{d s}=R_{s} i_{d s}+\dot{\varphi}_{s} \\
v_{q s}=R_{s} i_{q s}+\omega_{s} \varphi_{s}
\end{gathered}
$$

Suppose that the power supply network is stable, leading to a constant stator flux and a new stator voltage value:

$$
\begin{gathered}
v_{d s}=R_{s} i_{d s} \\
v_{q s}=R_{s} i_{q s}+\omega_{s} \varphi_{s}
\end{gathered}
$$

Substitute (15) in Eqs. (6), (7) and (14) we get:

$$
\begin{gathered}
i_{d s}=\frac{\varphi_{s}}{L_{s}}-\frac{M}{L_{s}} i_{d r} \\
i_{q s}=-\frac{M}{L_{s}} i_{q r} \\
T_{e m}=-1.5 p \frac{M}{L_{s}} \varphi_{s} i_{q r}
\end{gathered}
$$

By replacing stator currents with their expressions in the Eqs. (10) and (11), we find:

$$
\begin{gathered}
P_{S}=1.5\left(\frac{\omega_{s} \varphi_{s} M}{L_{s}} i_{q r}-\frac{V_{s}^{2}}{R_{S}}+\frac{\omega_{s}{ }^{2} \varphi_{s}^{2}}{R_{S}}\right) \\
Q_{s}=1.5\left(\frac{\omega_{s} \varphi^{2}{ }_{s}}{L_{s}}-\frac{\omega_{s} \varphi_{s} M}{L_{s}} i_{d r}\right)
\end{gathered}
$$

From the observation of Eqs. (23) and (24), we arrive at a decoupled power control, where the component $i_{q r}$ the rotor current controls the active power. The reactive power is operated by the direct component $i_{d r}$. By rearranging Eqs. (3) and (4), we can deduce a formula of rotor currents as a function of rotor voltages in Eqs. (25) and (26).

$$
\begin{gathered}
v_{d r}=R_{r} i_{d r}+\sigma L_{r} \frac{d i_{d r}}{d t}-g \omega_{s} \sigma i_{q r} \\
v_{q r}=R_{r} i_{d r}+\sigma L_{r} \frac{d i_{q r}}{d t}+g \omega_{s} \sigma i_{d r}+g \omega_{s} \frac{M \varphi_{s}}{L_{s}}
\end{gathered}
$$

Where, $\sigma=1-\frac{M^{2}}{L_{s} L_{r}}$ is the leakage factor and, $g=1-\frac{\omega_{r}}{\omega_{s}}$ is the slip. So the dynamic of the rotor currents is expressed in the Eqs. (27) and (28):

$$
\frac{d i_{d r}}{d t}=\frac{1}{\sigma L_{r}}\left(v_{d r}-R_{r} i_{d r}+g \omega_{s} \sigma i_{q r}\right)
$$

$$
\frac{d i_{q r}}{d t}=\frac{1}{\sigma L_{r}}\left(v_{q r}-R_{r} i_{q r}-g \omega_{s} \sigma i_{d r}-g \omega_{s} \frac{M \varphi_{s}}{L_{s}}\right)
$$

In established regime, the first terms derived from both Eqs. (25) and (26) are null and we can write:

$$
\begin{gathered}
v_{d r}=R_{r} i_{d r}-g \omega_{s} \sigma i_{q r} \\
v_{q r}=R_{r} i_{q r}+g \omega_{s} \sigma i_{d r}+g \omega_{s} \frac{M \varphi_{s}}{L_{s}}
\end{gathered}
$$

\subsection{Network-side converter equations}

In this section, we are interested in modelling the connection of the NSC to the electricity network via the $R_{f} L_{f}$ filter. Fig.3. illustrates the electrical model of the $R_{f} L_{f}$ connection filter.

From Fig. 3, we can write the following expressions in the three-phase reference frame, according to Kirchhoff's laws:

$$
\begin{aligned}
& v_{g 1}=-R_{f} i_{f 1}-L_{f} \frac{d i_{f 1}}{d t}+v_{f 1} \\
& v_{g 2}=-R_{f} i_{f 2}-L_{f} \frac{d i_{f 2}}{d t}+v_{f 2} \\
& v_{g 3}=-R_{f} i_{f 3}-L_{f} \frac{d i_{f 3}}{d t}+v_{f 3}
\end{aligned}
$$

Where $v_{g}$ is the network voltage, $i_{f}$ is networkfilter current, and $v_{f}$ is the network filter voltage supplied from the grid-side converter. By 


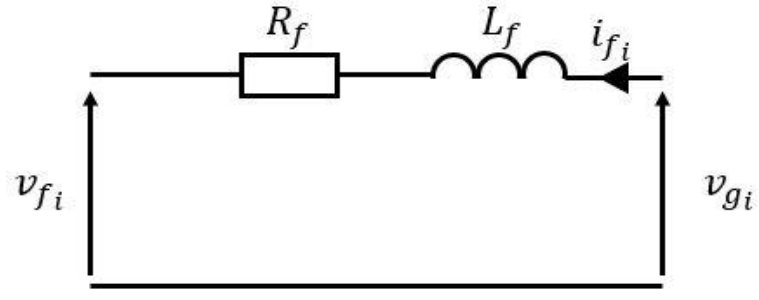

Figure. 3 Electric model of the $R_{f} L_{f}$ filter

applying Park's transformation to the three previous equations, we obtain:

$$
\begin{aligned}
& v_{f d}=R_{f} i_{f d}+L_{f} \frac{d i_{f d}}{d t}-\omega_{s} L_{f} i_{f q}+v_{g d} \\
& v_{f q}=R_{f} i_{f q}+L_{f} \frac{d i_{f q}}{d t}+\omega_{s} L_{f} i_{f d}+v_{g q}
\end{aligned}
$$

Where $v_{f d}, v_{f q}$ are the voltages at the output of GSC and $i_{f d}, i_{f q}$ are the corresponding currents injected into the network. The active and reactive powers generated by the GSC are defined by:

$$
\begin{gathered}
P_{f}=1.5\left(v_{g d} i_{f d}+v_{g q} i_{f q}\right) \\
Q_{f}=1.5\left(v_{g q} i_{f d}-v_{g d} i_{f q}\right)
\end{gathered}
$$

The d-axis of the reference frame is oriented with the network voltage angular position. Because the amplitude of the network voltage is constant, $v_{g d}$ is zero and $v_{g q}$ is constant.

$$
v_{g d}=v_{g} v_{g q}=0
$$

The Eqs. (34), (35), (36) and (37) become:

$$
\begin{gathered}
\frac{d i_{f d}}{d t}=-\frac{R_{f}}{L_{f}} i_{f d}+\omega_{s} i_{f q}-\frac{v_{g}}{L_{f}}+\frac{v_{f d}}{L_{f}} \\
\frac{d i_{f q}}{d t}=-\frac{R_{f}}{L_{f}} i_{f q}-\omega_{s} i_{f d}+\frac{v_{f q}}{L_{f}} \\
P_{f}=1.5\left(v_{g} i_{f d}\right) \\
Q_{f}=-1.5\left(v_{g} i_{f q}\right)
\end{gathered}
$$

From Eqs. (41) and (42), we observe that the flow of the active and reactive powers between the NSC and the network will be proportional to $i_{f d}$ and $i_{f q}$ respectively.The electrical model in Fig. 4 (a) illustrates the rotor, DC-LINK and converters circuits with their losses. From Fig. 4 (b), the equation of the power balance is written in Eq. (43).
Where $P_{c d c}$ instantaneous active power through the capacitor, $P_{r}$ rotor Active Power, $P_{f}$ filter Power, $p_{\text {filter_loss }}$ power loss in the filter, $p_{\text {conv_loss }}$ power loss in the converts RSC and GSC, $p_{d c \_l o s s}$ power loss in the DC-LINK capacitor .

$$
\begin{gathered}
P_{c_{d c}}=P_{f}-P_{r}-\left(p_{\text {filtre_loss }}+p_{\text {conv_loss }}+p_{d c_{\text {_loss }}}\right) \\
p_{\text {tot_loss }}: \text { total loss } \\
P_{c_{d c}}=c_{d c} v_{d c} \frac{d v_{d c}}{d t}=v_{d c} i_{d c}
\end{gathered}
$$

$p_{\text {filter_loss }}, p_{\text {conv_loss }}$ and $p_{d c_{-} \text {loss }}$ will be taken into account in this work because it significantly affects the system, especially in the event of a network dips. Substituting in the Power expressions from Eqs. (12), (41) and (44), the voltage state model through the capacitor of the DC-LINK is written in Eq. (45):

$$
v_{d c} \frac{d v_{d c}}{d t}=\frac{1.5}{C_{d c}}\left(v_{g} i_{f d}\right)-\frac{P_{r}+p_{\text {tot-loss }}}{C_{d c}}
$$

$R_{\text {conv_loss }}$ : Represents the total switching loss of the converters

$R_{d c_{-} \text {loss }}:$ Represents the losses in the capacitor of the DC- LINK

With:

- $\quad R_{\text {conv_loss }} R_{R S C \_l o s s} / / R_{N S C \_l o s s}$

- $\quad p_{\text {conv_loss }}=\frac{v^{2} d c}{R_{\text {conv_loss }}} ; p_{d c \_l o s s}=\frac{v^{2} d c}{R_{d c \_l o s s}}$ $p_{\text {filter_loss }}=R_{f} i_{f}^{2}$

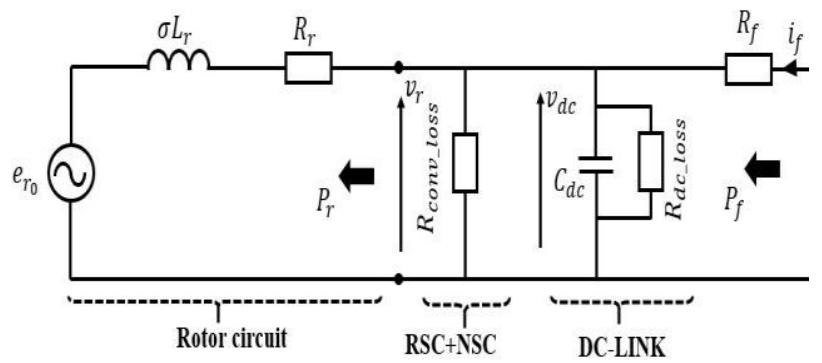

(a)

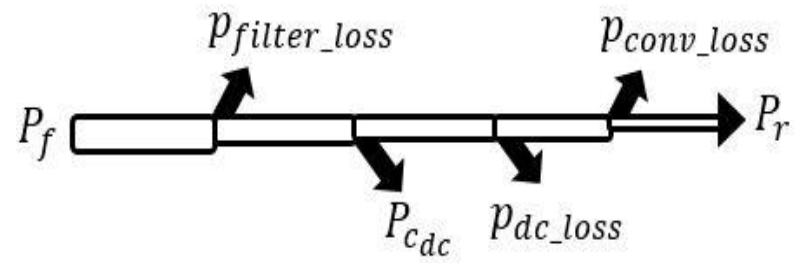

(b)

Figure. 4 Real model of losses in: (a) the connection circuit and (b) associated power shaft 


\section{Principle of SOSMC}

The theory of SOSMC $[6,20]$ is an alternative to the problem of CSMC. In this approach, the term discontinuous no more appears directly in the synthesized control but in one of its superior derivatives, which has the advantage of reducing the chattering. The SOSMC was introduced to overcome the chattering problem while maintaining the finitetime convergence and robustness properties of conventional sliding mode controls and improving asymptotic precision. For this purpose, a supertwisting algorithm (STA) control algorithm capable of generating control laws of all second-order systems.

\subsection{Stator powers control through the rotor-side converter}

The rotor currents that are related to the active and reactive powers by Eqs. (23) and (24) must follow the appropriate current references so that a SOSMC based on the Park reference frame above is used. To ensure the convergence of the active and reactive powers of the DFIG stator in their references, the rotor current references $\mathrm{d}-\mathrm{q}$ are defined by.

$$
\begin{gathered}
i_{\text {qr-ref }}=\frac{L_{S}}{\omega_{s} \varphi_{s} M}\left(\frac{P_{s-r e f}}{1.5}+\frac{V_{s}{ }^{2}}{R_{s}}-\frac{\omega^{2}{ }_{s} \varphi^{2}}{R_{S}}\right) \\
i_{d r-r e f}=-\frac{L_{S}}{\omega_{s} \varphi_{s} M}\left(\frac{Q_{s-r e f}}{1.5}-\frac{\omega_{s} \varphi_{s}{ }^{2}}{L_{S}}\right)
\end{gathered}
$$

The sliding surfaces representing the error between the measured and references rotor currents are defined by:

$$
s_{q}=i_{q r}-i_{q r-r e f} ; s_{d}=i_{d r}-i_{d r-r e f}
$$

The dynamics of the sliding functions $s_{q}$ and $s_{d}$ are defined by:

$$
\begin{aligned}
& \frac{d s_{q}}{d t}\left(i_{q r}\right)= \frac{1}{\sigma L_{r}}\left(v_{q r}-R_{r} i_{q r}-g \omega_{s} \sigma i_{d r}-\right. \\
&\left.g \omega_{s} \frac{M \varphi_{s}}{L_{s}}\right)-\frac{d i_{q r-r e f}}{d t} \\
& \frac{d s_{d}}{d t}\left(i_{d r}\right)= \frac{1}{\sigma L_{r}}\left(v_{d r}-R_{r} i_{d r}+g \omega_{s} \sigma i_{q r}\right)- \\
& \frac{d i_{d r-r e f}}{d t}
\end{aligned}
$$

If we define functions $F_{1}$ and $F_{2}$ as follows:

$$
\begin{gathered}
F_{1}=\frac{1}{\sigma L_{r}}\left(-R_{r} i_{q r}-g \omega_{s} \sigma i_{d r}-g \omega_{s} \frac{M \varphi_{s}}{L_{s}}\right) \\
-\frac{d i_{q r-r e f}}{d t} \\
F_{2}=\frac{1}{\sigma L_{r}}\left(-R_{r} i_{d r}+g \omega_{s} \sigma i_{q r}\right)-\frac{d i_{d r-r e f}}{d t}
\end{gathered}
$$

Such that:

$\frac{d^{2} s_{q}}{d t^{2}}\left(i_{q r}\right)=\frac{1}{\sigma L_{r}} \dot{v}_{q r}+\dot{F}_{1} ; \frac{d^{2} s_{d}}{d t^{2}}\left(i_{d r}\right)=\frac{1}{\sigma L_{r}} \dot{v}_{d r}+\dot{F}_{2}$

The STA is used to generate control laws [6]. This algorithm for the SOSMC was proposed by EMELYANOV in 1990 contains two parts [6, 20]:

$$
\begin{aligned}
& v_{q r}=u_{1}-\beta_{1}\left|s_{q}\right|^{\frac{1}{2}} \operatorname{sign}\left(s_{q}\right) ; \dot{u}_{1}=-\lambda_{1} \operatorname{sign}\left(s_{q}\right) \\
& v_{d r}=z_{1}-\beta_{2}\left|s_{d}\right|^{\frac{1}{2}} \operatorname{sign}\left(s_{d}\right) ; \dot{z}_{1}=-\lambda_{2} \operatorname{sign}\left(s_{d}\right)
\end{aligned}
$$

To ensure convergence within a short time, the parameter $\lambda_{i}$ and $\beta_{i}$ must verify the following inequalities:

$$
\lambda_{i}>\frac{\gamma_{i}}{\sigma L_{r}} ; \beta_{i} \geq \frac{4 \gamma_{i}\left(\lambda_{i}+\gamma_{i}\right)}{\sigma^{2} L_{r}^{2}\left(\lambda_{i}-\gamma_{i}\right)} ;\left|\dot{F}_{i}\right|<\gamma_{i} ; i=1,2
$$

On the other hand, the equivalent controls are calculated by setting to zero (49) and (50), as follows:

$$
\begin{gathered}
v_{q r-e q}=R_{r} i_{q r}+g \omega_{s} \sigma i_{d r}+g \omega_{s} \frac{M \varphi_{s}}{L_{s}}+ \\
\sigma L_{r} \frac{d i_{q r-r e f}}{d t} \\
v_{d r-e q}=R_{r} i_{d r}+g \omega_{s} \sigma i_{q r}+\sigma L_{r} \frac{d i_{d r-r e f}}{d t}
\end{gathered}
$$

\subsection{Control of the DC-LINK voltage and the reactive power of the filter through the network-side converter}

The function of the network-side converter control is to ensure that the voltage of the DC-LINK is not changed and to annul the reactive power of the $R_{f} L_{f}$ filter. this must be to synthesize control laws that are resistant to disturbances. In equation Eq. (45) of the voltage across the DC-LINK, the term $p_{\text {tot_loss }}$ represent the total losses in the connection chain that must be available. This term is inaccessible for measurement with a real sensor. We, 
therefore, suggest the use of a software sensor, which is called the $\mathrm{KO}$ to calculate an estimate of this term in real-time, and in a closed loop with the controller. In addition, the use of an observer minimizes the cost of the real sensor and since the observers serve as a filter, measurement noise is eliminated.

\subsubsection{Observability of the DC-LINK system}

First, before making the concept of the KO, it is necessary to verify that the DC-LINK system is observable. Eq. (56) illustrates the dynamic model of the voltage across the DC-LINK capacitor.

$$
v_{d c} \frac{d v_{d c}}{d t}=\frac{1.5}{C_{d c}}\left(v_{g} i_{f d}\right)+\frac{(\mathrm{t})}{\frac{\left(-P_{r}-p_{\text {tot-loss }}\right)}{C_{d c}}}
$$

For convenience, the variables were chosen as follows (56).

$$
\begin{aligned}
& x_{1}=\frac{v_{d c}^{2}}{2} ; x_{2} \\
& =-\frac{\left(P_{r}^{2}+p_{\text {filtre-loss }}+p_{\text {conv-loss }}+p_{d c-\text { loss }}\right)}{c_{d c}} \\
& =-\frac{\left(P_{r}+p_{\text {tot-loss }}\right)}{c_{d c}}=\frac{p(t)}{C_{d c}}
\end{aligned}
$$

The resulting state model representing the DCLINK voltage is now Eq. (57), where $x_{2}$ represents the term to be observed.

$$
\begin{gathered}
X=\left(x_{1} x_{2}\right)^{T}, Y=x_{1}=\frac{v^{2} d c}{2}, U=i_{f d} ; A \\
=(01 ; 00)^{T} \\
B=(\alpha 0)^{T}, C=(10) \\
\dot{x}_{1}=x_{2}+\alpha i_{f d} ; \dot{x}_{2}=\phi(t) ; Y=x_{1} ; \alpha=1.5 \frac{v_{g}}{c_{d c}}
\end{gathered}
$$

The previous state model can be rewritten in the following general form:

$$
\dot{X}=A X+B U ; Y=C X
$$

The observability of the DC-LINK system is verified by the determinant of the observability matrix $O_{o b s}$, this last must be different from zero:

$$
\operatorname{det}\left(o_{o b s}\right)=\operatorname{det}\left(\begin{array}{l}
C \\
C A
\end{array}\right)=\operatorname{det}\left(\begin{array}{l}
10 \\
01
\end{array}\right)=1 \neq 0
$$

Consequently, the system Eq. (58) is completely observable.

\subsubsection{Concept of the KO}

The design of the KO is based on the recopy of the state model of the subsystem of Eq. (58) with a gain matrix of adjustment $L$, so the KO state model is written in Eq. (59).

$$
\dot{\hat{X}}=A \hat{X}+B U+L(Y-\hat{Y}) ; \hat{Y}=C \hat{X} ; L=\left(l_{1} l_{2}\right)^{T}
$$

We define the estimation error as follows:

$$
\tilde{X}=X-\hat{X}
$$

The error dynamics are guided by the following system:

$$
\dot{\tilde{X}}=\dot{X}-\dot{\hat{X}}=(A-L C) \tilde{X}
$$

We introduced $A^{\prime}=A-L C$, is chosen so that it is a Hurwitz matrix b appropriate choice of vector $L$, $\tilde{X}=X-\hat{X}$ is sure to converge exponentially to 0.From the Eqs. (59) and (61), th dynamics of the estimated states are expressed by:

$$
\dot{\hat{x}}_{1}=\hat{x}_{2}+\alpha i_{f d}+l_{1} \tilde{x}_{1} ; \dot{\hat{x}}_{2}=l_{2} \tilde{x}_{1}
$$

\subsubsection{DC-LINK voltage and filter reactive power control}

\subsubsection{DC-LINK voltage control}

The main objective of the proposed PIC is to maintain the value of the voltage across the DCLINK. Fig.5 shows the block diagram of the DCLINK voltage control. From Eq (56), we have:

$$
P_{f}=P_{c_{d c}}+p(t)=1.5 v_{g} i_{f d}
$$

By adjusting the $P_{f}$ power, it is then possible to control the $P_{c d c}$ power in the capacitor and thus control the DC-LINK voltage. To do this, the powers $p(t)$ and $P_{c d c}$ must be known to determine $P_{f-r e f .} p(t)$ is a perturbation seen by the control chain that will be measured by the KO. The power reference for the capacitor is related to the circulating reference current in the capacitor:

$$
P_{c_{d c}-r e f}=v_{d c} i_{d c-r e f}
$$

The transfer function of the DC-LINK system is: 
Laplace transform

$$
i_{d c}=C_{d c} \frac{d v_{d c}}{d t} \Rightarrow \frac{v_{d c}(s)}{I_{d c}(s)}=\frac{1}{C_{d c} s}
$$

\subsubsection{Filter Reactive Power Control}

The filter currents that are related to the active and reactive powers exchanged between the NRC and the network by Eqs. (41) and (42) must follow the appropriate current references so that a SOSMC based on the above Park reference is used. To ensure the convergence of the active and reactive powers passing through the filter in their references, the current reference $i_{f d-r e f}$ of the filter is generated by the voltage regulation loop $V_{d c}$ and the current reference $i_{f q-r e f}$ of the filter is defined by:

$$
i_{f q-r e f}=-\frac{Q_{f-r e f}}{1.5 v_{g}}
$$

The sliding surfaces representing the error between the measured and references filter currents are defined by:

$$
s_{f d}=i_{f d}-i_{f d-r e f} ; s_{f q}=i_{f q}-i_{f q-r e f}
$$

The dynamics of the sliding functions $s_{f d}$ and $s_{f q}$ are defined by:

$$
\begin{gathered}
\frac{d s_{f d}}{d t}\left(i_{f d}\right)=-\frac{R_{f}}{L_{f}} i_{f d}+\omega_{s} i_{f q}-\frac{v_{g}}{L_{f}}+\frac{v_{f d}}{L_{f}}- \\
\frac{d i_{f d-r e f}}{d t} \\
\frac{d s_{f q}}{d t}\left(i_{f q}\right)=-\frac{R_{f}}{L_{f}} i_{f q}-\omega_{s} i_{f d}+\frac{V_{f q}}{L_{f}}-\frac{d i_{f q-r e f}}{d t}
\end{gathered}
$$

If we define functions $H_{1}$ and $H_{2}$ as follows:

$$
\begin{gathered}
H_{1}=-\frac{R_{f}}{L_{f}} i_{f d}+\omega_{s} i_{f q}-\frac{v_{g}}{L_{f}}-\frac{d i_{f d-r e f}}{d t} \\
H_{2}=-\frac{R_{f}}{L_{f}} i_{f q}-\omega_{s} i_{f d}-\frac{d i_{f d-r e f}}{d t}
\end{gathered}
$$

Such that

$\frac{d^{2} s_{f d}}{d t^{2}}\left(i_{f d}\right)=\dot{H}_{1}+\frac{1}{L_{f}} \dot{v}_{f d} ; \frac{d^{2} i_{f q}}{d t^{2}}\left(i_{f q}\right)=\dot{H}_{2}+\frac{1}{L_{f}} \dot{v}_{f q}$ [6]:

The STA is used to generate control laws reals

$$
v_{f d}=u_{1}^{\prime}-\rho_{1}\left|s_{f d}\right|^{\frac{1}{2}} \operatorname{sign}\left(s_{f d}\right) ; \dot{u}_{1}^{\prime}=
$$

$$
\begin{gathered}
-\sigma_{1} \operatorname{sign}\left(s_{f d}\right) \\
v_{f q}=u_{2}^{\prime}-\rho_{2}\left|s_{f q}\right|^{\frac{1}{2}} \operatorname{sign}\left(s_{f q}\right) ; \dot{u}_{2}^{\prime}= \\
-\sigma_{2} \operatorname{sign}\left(s_{f q}\right)
\end{gathered}
$$

To ensure convergence within a short time, the param $\mu$ and $\eta$ must verify the following inequalities:

$$
\sigma_{i}>\frac{\delta_{i}}{L_{f}} ; \rho_{i} \geq \frac{4 \delta_{i}\left(\sigma_{i}+\delta_{i}\right)}{L^{2}\left(\sigma_{i}-\delta_{i}\right)} ;\left|\dot{H}_{i}\right|<\delta_{i} ; i=1,2
$$

On the other hand, the equivalent controls are calculated by setting to zero Eqs. (68) and (69), as follows:

$$
v_{f d-e q}=R_{f} i_{f d}-L_{f} \omega_{s} i_{f q}+v_{g}+L_{f} \frac{d i_{f d-r e f}}{d t}
$$

$$
v_{f q-e q}=R_{f} i_{f q}+L_{f} \omega_{s} i_{f d}+L_{f} \frac{d i_{f q-r e f}}{d t}(74)
$$

\section{Simulation and discussion of results}

The DFIG-based wind turbine, as illustrated in Fig.1, is used to test the performance of the designed controller. The system in Fig.1 represents the grouping of thirty wind turbines and each of these has a capacity of $2 \mathrm{MW}$. The detailed simulation model is developed in MATLAB using the MATLAB/SIMULINK SimPowerSystems toolbox based on the DFIG-based wind turbine. The list of parametrs values of DFIG, network filter, SOSMC, $\mathrm{PI}$ and $\mathrm{KO}$ is given in Tables 1, 2, and 3 following.

A fault case is taken into account to analyse the capacity of the DFIG to cross the fault using the nonlinear SOSMC coupled with a KO designed for this effect. The performance of the designed SOSMC is also compared to existing strategies in the literature $[10,11-13]$ in Section 5.2.1. In this case, study, a symmetrical voltage dip fault, which is the most critical fault on power networks and has a significant impact on the stability of wind farms that require support to cross it, is applied on the network. The fault is applied in the form of a symmetrical voltage dip of $100 \%$ at $t=0.85 \mathrm{~s}$ for a duration of $0.15 \mathrm{~s}$, i.e. the fault is eliminated at $\mathrm{t}=1 \mathrm{~s}$.Simulation results under SOSMC will be tested and analyzed for two different scenarios:(1) network voltage dip fault without PPM, (2) network voltage dip fault with PPM. 


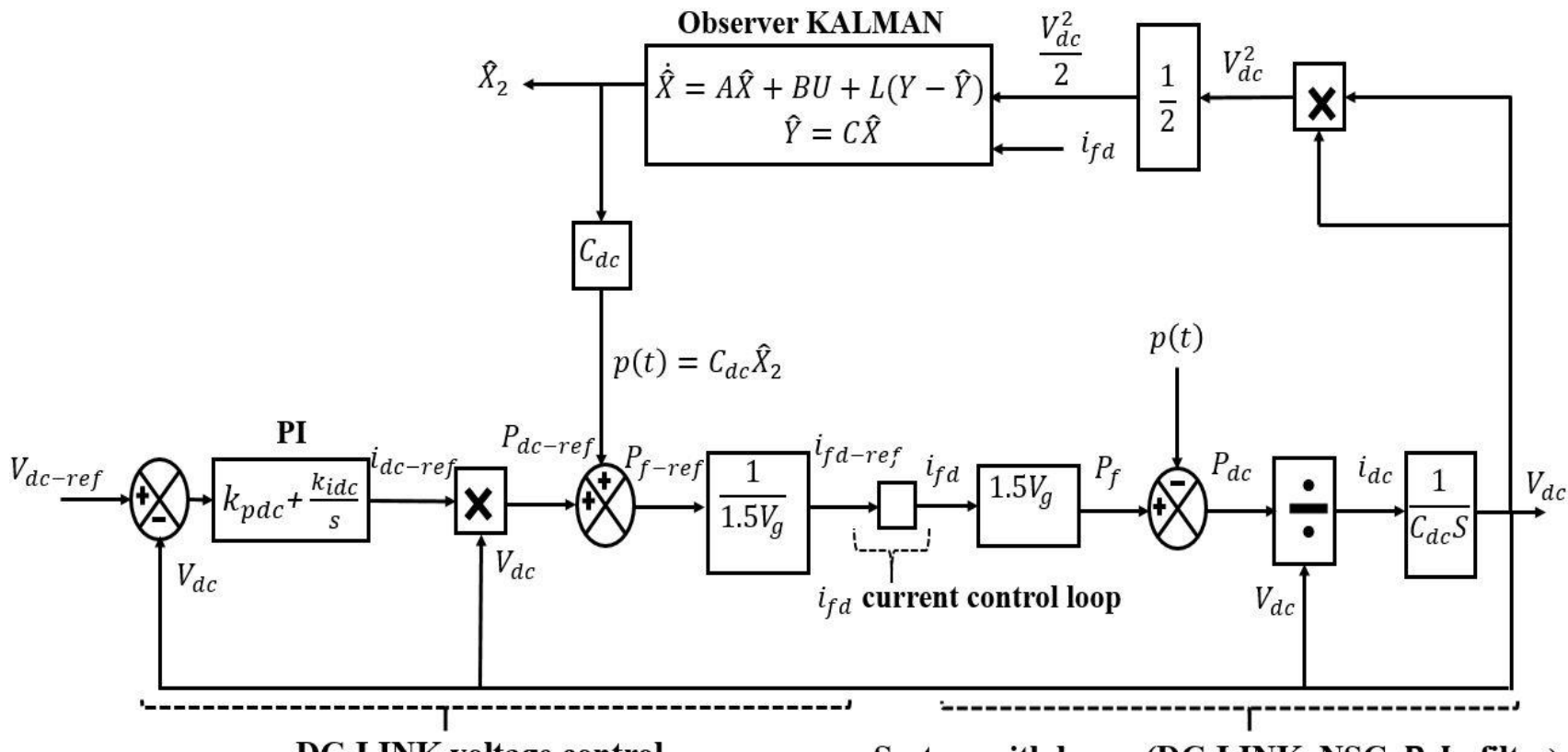

DC-LINK voltage control

System with losses (DC-LINK, NSC, $\mathbf{R}_{\mathrm{f}} \mathbf{L}_{\mathrm{f}}$ filter)

Figure.5 DC-LINK voltage control loop

Table 1. Simulation parameters for a DFIG

\begin{tabular}{|c|c|}
\hline Parameter & Value \\
\hline Rated power & $\boldsymbol{P}_{\boldsymbol{n}}=2 \mathrm{MW}$ \\
\hline Stator nominal voltage & $\boldsymbol{V}_{\boldsymbol{s} \boldsymbol{n}}=690 \mathrm{~V}$ \\
\hline Nominal frequency & $f=50 \mathrm{~Hz}$ \\
\hline Number of pole pairs & $p=2$ \\
\hline Stator resistance & $\boldsymbol{R}_{\boldsymbol{s}}=0.023 \mathbf{p .} \mathbf{u}$ \\
\hline Rotor resistance & $\boldsymbol{R}_{\boldsymbol{r}}=0.016 \mathbf{p .} \mathbf{u}$ \\
\hline Stator inductance & $\boldsymbol{L}_{\boldsymbol{s}}=0.18 \mathbf{p} \mathbf{u}$ \\
\hline Rotor inductance & $\boldsymbol{L}_{\boldsymbol{r}}=\mathbf{0 . 1 8} \mathrm{p} . \mathrm{u}$ \\
\hline Mutual inductance & $M=2.9 \mathrm{p} . \mathbf{u}$ \\
\hline DC-LINK voltage & $\boldsymbol{V}_{\boldsymbol{d} \boldsymbol{c}}=\mathbf{1 2 0 0} \boldsymbol{V}$ \\
\hline
\end{tabular}

$*$ p.u= per unit

Table 2. Parameters of network filter

\begin{tabular}{|c|c|}
\hline Parameter & Value \\
\hline Inductance of the filter & $L_{f}=0.3 \mathrm{p.u}$ \\
\hline Resistance of the filter & $R_{f}=0.003 \mathrm{p.u}$ \\
\hline Resistance of the filter & $C_{d c}=10^{-2} \mathrm{~F}$ \\
\hline
\end{tabular}

Table 3. Parameters of SOSMC, PI and KO

\begin{tabular}{|c|c|c|c|c|c|}
\hline Parameter & $\beta_{1}$ & $\beta_{2}$ & $\lambda_{1}$ & $\lambda_{2}$ & $\rho_{1}$ \\
\hline Value & 1.5 & 200 & 50 & 1000 & 1.5 \\
\hline Parameter & $\rho_{2}$ & $\sigma_{1}$ & $\sigma_{2}$ & $l_{1}$ & $l_{2}$ \\
\hline Value & 200 & 50 & 1000 & 2500 & 25000 \\
\hline Parameter & \multicolumn{3}{|c|}{$k_{p d c}$} & \multicolumn{2}{|c|}{$k_{i d c}$} \\
\hline Value & \multicolumn{3}{|c|}{1.45} & \multicolumn{2}{c|}{27.7} \\
\hline
\end{tabular}

\subsection{Behavior of the DFIG in situation of voltage dip without PPM}

Fig. 7 shows the rotor current response during the fault with the strategy SOSMC. The rotor current

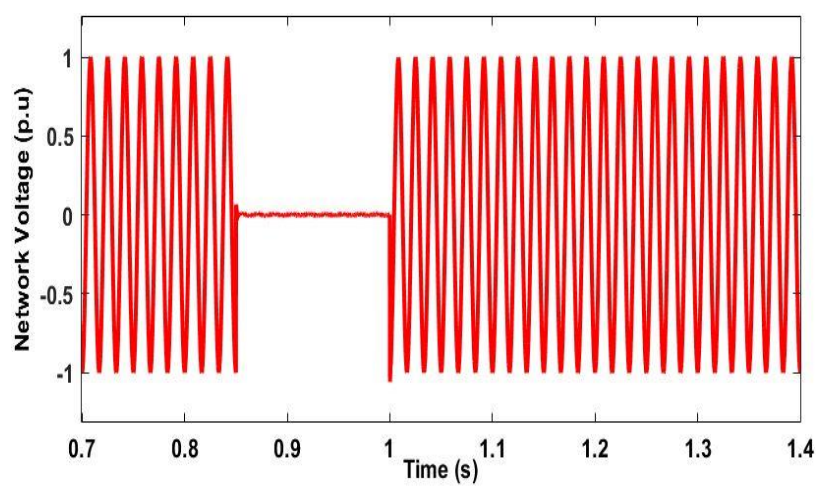

Figure.6 Network Voltage 60KV

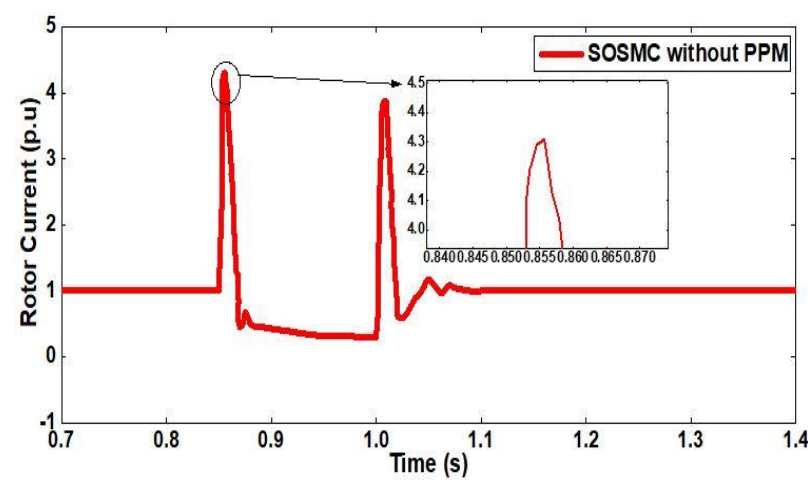

Figure.7 Rotor current without passive protection Using $\left(\mathrm{I}_{\mathrm{r}-\mathrm{ref}}=1 \mathrm{p} . \mathrm{u}\right)$

reaches high overcurrents at the onset of the fault and reaches the value of 4.3 p.u with strong oscillations at the time of fault termination.

As shown in Fig. 8, the active power response, its value reaches $1.1 \mathrm{p}$. $\mathrm{u}$ when the fault occurs and then decreases rapidly to zero for the rest of the fault duration. When the grid voltage recovers, with SOSMC, it starts to decrease until 1.02s, then it starts 


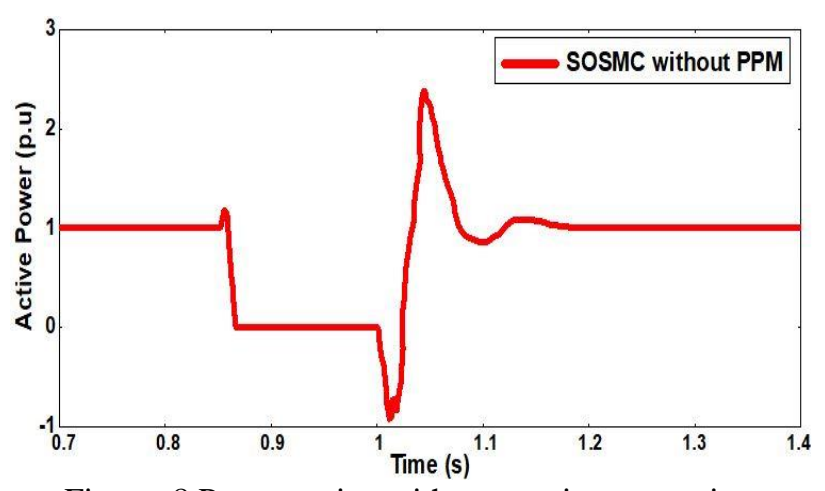

Figure. 8 Power active without passive protection Using $\left(\mathrm{P}_{\mathrm{s}-\mathrm{ref}}=1 \mathrm{p} . \mathrm{u}\right)$

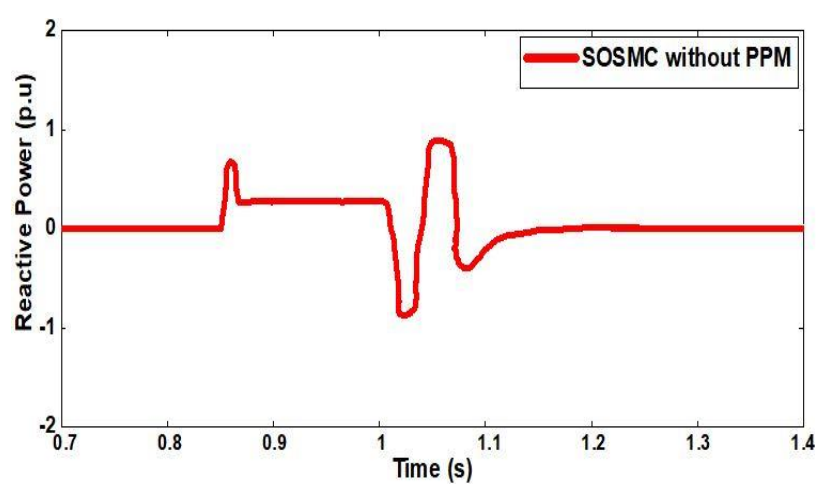

Figure. 9 Power Reactive without passive protection using $\left(\mathrm{Q}_{\mathrm{s}-\mathrm{ref}}=0 \mathrm{p} . \mathrm{u}\right)$

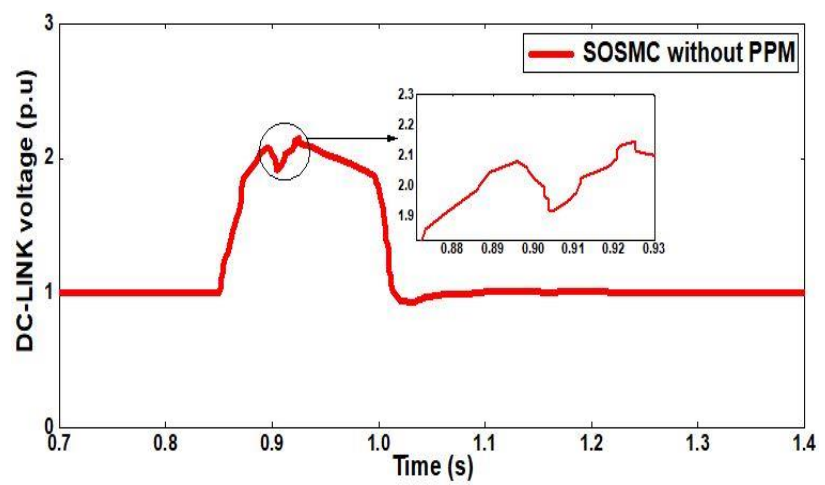

Figure. 10 DC-LINK voltage without passive protection using $\left(\mathrm{V}_{\mathrm{dc}-\mathrm{ref}}=1 \mathrm{p} . \mathrm{u}\right)$

to increase again with a strong oscillation.

Fig. 9 shows the response of the reactive power with SOSMC during a voltage dip. When the grid voltage is restored, the reactive power has a strong oscillation and a transient time to return to the prefault reference value of $150 \mathrm{~ms}$.

As shown in Fig. 10, the voltage response of the DC-LINK under the SOSMC strategy during a voltage dip. Between $0.85 \mathrm{~s}$ and $1 \mathrm{~s}$, an overvoltage is observed across the DC-LINK capacitor with this strategy. While the overvoltage reaches to $2.1 \mathrm{p} . \mathrm{u}$ with the SOSMC. However, with this strategy the DC-LINK voltage has a low oscillation regime after the faults are eliminated.

\subsection{Behaviour of the DFIG in situation of voltage dip with PPM}

The performance of the wind system during a voltage dip with SOSMC strategie is unsatisfactory. In this section, we introduce a PPM that contains two crowbar and DC-chopper circuits to the control strategies used in the previous section to improve the performance of the wind power system during a voltage dip in the power network. Firstly, the Crowbar circuit is utilized to limit the rotor current during the fault; it is placed between the rotor and the RSC converter, as shown in fig. 1; this consists of a resistor and an IGBT switch. Secondly, the "DCchopper" circuit is used to limit the overvoltage at the terminals of the DC-LINK capacitor during the fault; it is connected in parallel with the DC-LINK. The optimal choice of the value of the crowbar resistance is given by [19] and expressed in Eq. (75).

$$
R_{c r-o p t}=\sqrt{\frac{2\left(V_{r \max } \omega_{s} L_{s}\right)^{2}}{3.2 V_{s}^{2}-2 V_{r \max }^{2}}}
$$

Concerning the operation of these two protection circuits is made by the flowchart of the activationinactivation management shown in Fig. 11.

Fig. 12 shows the dynamics of the rotor current in the SOSMC strategy with the PPM activated. Indeed, with the addition of PPM to SOSMC, the system presents a better limitation of the rotor current peaks. When the fault occurs, the current reaches 1.45 p.u, and when the network recovers the voltage, the current shows a low oscillation.

As shown in Fig. 13 the response of the active power, its value reaches $1.1 \mathrm{p}$. $\mathrm{u}$ when the fault occurs and then rapidly decreases to zero for the rest of the fault duration. When the mains voltage recovers, with the SOSMC, it starts to decrease until 1.02s,

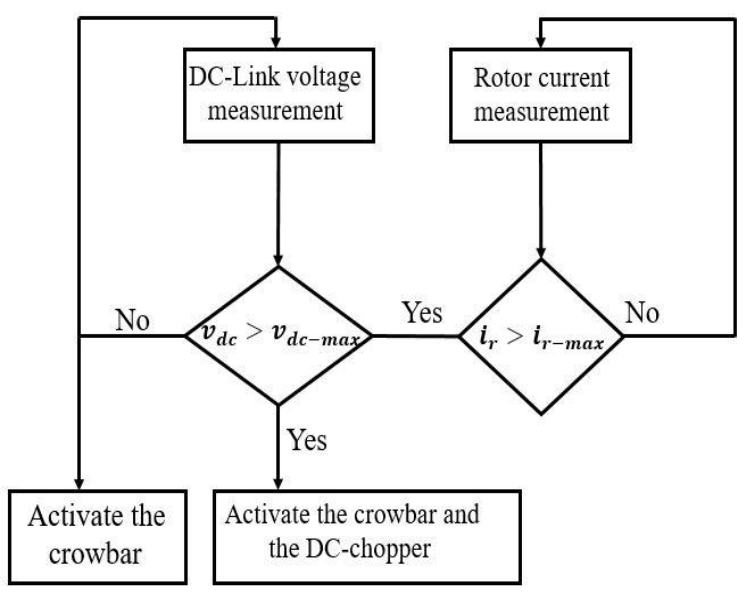

Figure. 11 Flowchart of the protection system management 


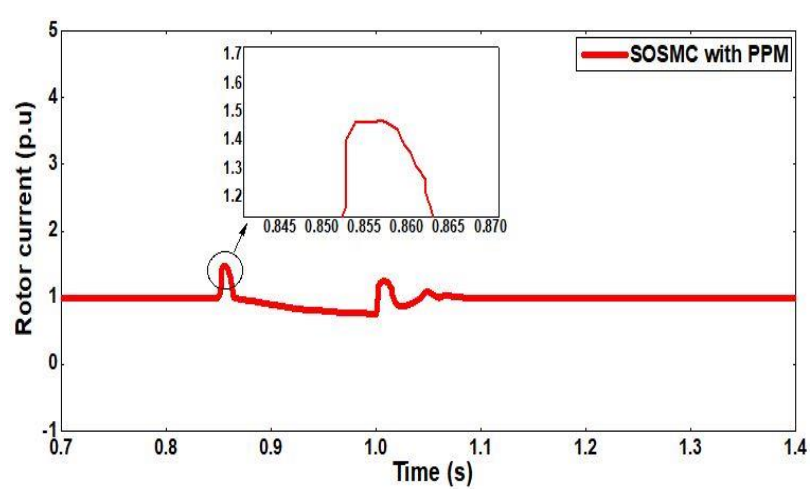

Figure. 12 Rotor current with passive protection using $\left(\mathrm{I}_{\mathrm{r}-\mathrm{ref}}=1 \mathrm{p} . \mathrm{u}\right)$

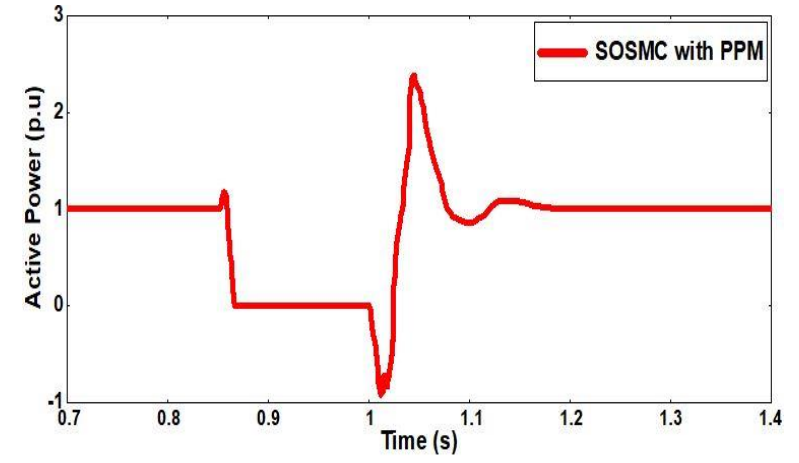

Figure.13 Power active with passive protection using $\left(\mathrm{P}_{\mathrm{s}-}\right.$ ref $=1$ p.u)

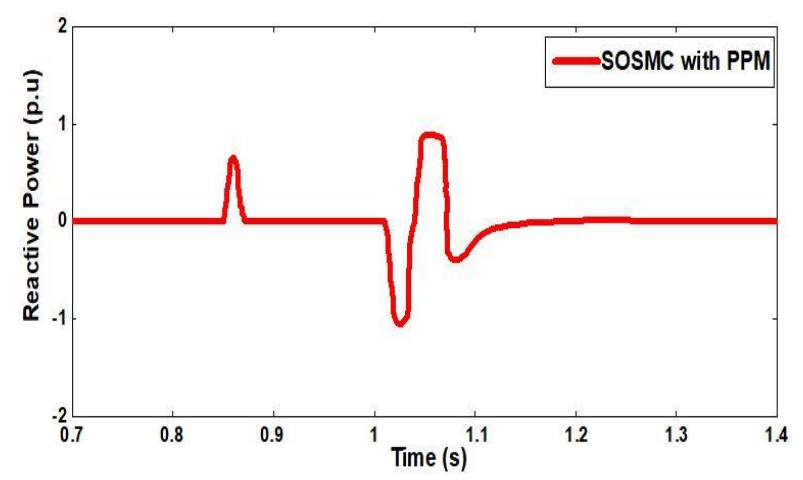

Figure. 14 Power Reactive with passive protection using $\left(\mathrm{Q}_{\text {s-ref }}=0\right.$ p.u $)$

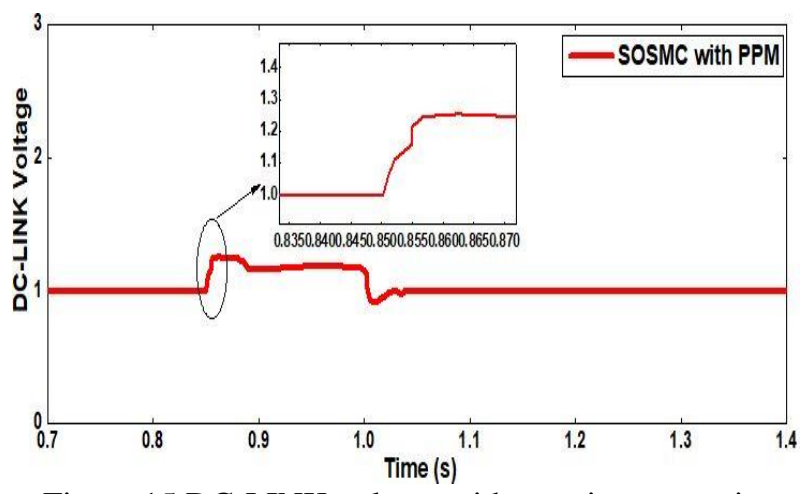

Figure.15 DC-LINK voltage with passive protection using $\left(\mathrm{V}_{\mathrm{dc}-\mathrm{ref}}=1 \mathrm{p} . \mathrm{u}\right)$ then it starts to increase again with a strong oscillation .

Fig. 14 shows the reactive power response with the SOSMC under activation of the PPM during a voltage dip. At the time of the fault, the reactive power increases and reaches a reduced value of 0.6p.u with the control strategy. Then, during the voltage drop, the reactive power supplied by the wind system remains zero, which is why the power factor at the connection point is close to unity; thus, the system supports the grid with the fault, then after the recovery of the grid voltage with SOSMC the reactive power reaches a small negative value of 1 p.u at time $1.03 \mathrm{~s}$ and reaches a steady state after a duration of $130 \mathrm{~ms}$ with strong oscillations.

As shown in Fig. 15, the DC-LINK voltage increases above its reference value of $1 \mathrm{p} . \mathrm{u}$ at the time of the fault, which means that the capacitor has been overcharged. The SOSMC, under the same PPM ,limits however the overvoltage in satisfactory values of the DC-LINK capacitor. In addition, the oscillation behavior of the DC-LINK voltage after elimination of the fault remains by the low.

\subsubsection{Comparison to other methods in the Literature}

After demonstrating the peak limitation of the DFIG quantities during the voltage dip and the robustness of crossing the fault without destruction of the proposed controller, it is interesting to compare it with similar techniques in the literature to demonstrate its advantages and superiority. It is emphasized here that the above-mentioned techniques are not performed under the same constraints and conditions on the network in which the wind farm is connected, it is very rare to find many works performed under similar conditions. Based on this comparison, the proposed solution of the SOSMC with KO has robustness at the point of spike limitation and low oscillation. Thus, the Adaptadtive Backstepping controller (ABC) with High Gain Observer (HGO) presented by O.S.Adekanle (2018) [13] has Moderate-low Robustness against peaks limitation than our Technical. Also, the proposed solution has a better limitation of rotor current and DC-LINK voltage values during a voltage dip, compared to adaptive backstepping with a high gain observer [13], sliding mode [11], and proportional-integral controls [11]. Table 4 shows a synthesis of the performance characteristics of the published controllers and our proposal. Based on this comparison, the superiority of SOSMC-KO with PPM is proven. 
Table 4. The comparison between our results and other methods published

\begin{tabular}{|c|c|c|c|c|c|}
\hline \multirow[t]{2}{*}{$\begin{array}{c}\text { Publication } \\
\text { paper }\end{array}$} & \multirow[t]{2}{*}{$\begin{array}{l}\text { Technic } \\
\text { methods }\end{array}$} & \multicolumn{2}{|c|}{$\begin{array}{l}\text { With PPM during } \\
\text { voltage dip }\end{array}$} & \multirow{2}{*}{$\begin{array}{c}\text { Robustness } \\
\text { against peaks } \\
\text { limitation }\end{array}$} & \multirow{2}{*}{$\begin{array}{c}\text { Oscillation at } \\
\text { the time of } \\
\text { fault } \\
\text { elimination }\end{array}$} \\
\hline & & $\operatorname{Ir}(\mathbf{p u})$ & $V d c(\mathrm{pu})$ & & \\
\hline $\begin{array}{l}\text { N.H.Saad } \\
(\mathbf{2 0 1 5})[11]\end{array}$ & PIC & 3.5 & 1.11 & Not robust & High \\
\hline $\begin{array}{l}\text { N.H.Saad } \\
(2015)[11] \\
\end{array}$ & SMC & 5 & 0.1 & Not robust & High \\
\hline $\begin{array}{c}\text { O.S.Adekanle } \\
\text { (2018)[13] }\end{array}$ & $\mathbf{A B C}$ & 2.2 & 0.41 & Moderate-robust & low \\
\hline $\begin{array}{c}\text { Our Proposed } \\
\text { technique }\end{array}$ & SOSMC & 1.45 & 1.2 & Robust & Low \\
\hline
\end{tabular}

\section{Conclusion}

This paper deals with the modelling and control of a DFIG taking into account all stator parameters to bring the system closer to reality for the real active and reactive power equations. It also minimizes rotor current and DC-LINK voltage surges and improves reactive power in the case of a voltage dip in the network. This modification gives safe and accepted results in simulation, which is not the case of many researchers who previously neglected it.

A robust non-linear control technique using SOSMC is used to control the active and reactive power through RSC and the DC-LINK voltage with the reactive power through NSC of a networkconnected $2 \mathrm{MW}$ wind power system. When a voltage dip is detected in the network this control technique is combined with a $\mathrm{KO}$ is designed to estimate the power generated on the rotor side of the DFIG, the power losses in the RSC, NSC converters, and the DC-LINK capacitor to make the control strategy more efficient and without the influence of the measurement noise introduced by the sensors.

A PPM includes crowbar and DC-chopper is added to the control technique used to increase the results found show that the addition of the PPM was able to reduce the rotor current and bring the DCLINK voltage below acceptable values during the fault.

The performance of the designed SOSMC is also compared to existing strategies in the literature in case network voltage dip fault with activation of the PPM capacity of the system to overcome the fault in the $60 \mathrm{KV}$ electrical network..

The SOSMC is able to limit the current overshoot to less than 2p.u and DC-LINK overvoltage less than or equal to $1.5 \mathrm{p}$.u during the voltage dip.

The topic of our future research may include the development of an non-linear Adaptive Direct Power Controllers with PPM for DFIG against the asymmetrical voltage dips and the hardware implementation of the proposed strategy. The following appendix presents the definitions of all the variables used in this paper.

\section{Conflicts of Interest}

The authors declare no conflict of interest

\section{Author Contributions}

Azeddine Loulijat and Najib Ababssi performed the study of SOSMC strategie and KO and the structure of the paper. Azeddine Loulijat modeled the proposed DFIG-based wind power system under MATLAB/SIMULINK. Azeddine Loulijat and Makhad Mohamed wrote the paper. Najib Ababssi and Makhad Mohamed contributed to reviewing the paper. All authors read and approved the final manuscript.

\section{References}

[1] O. S. Adekanle, M. Guisser, E. Abdelmounim, and M. Aboulfatah, "Nonlinear Controller with Rotor Crowbar and DC-Chopper Fault Ride Through Technique for Grid-Connected Doubly-Fed Induction Generator", International Review of Automatic Control, Vol. 11, No. November, pp. 281-292, 2018.

[2] A. M. Eltamaly, A. Alolah, and H. M. Farh, "3 authors: Ali M. Eltamaly Mansoura University 145", New Developments in Renewable Energy, 2013.

[3] C. O. F. Dfig, "Control of Dfig", Power Eng., No. February, 2003.

[4] M. Chakib, T. Nasser, and A. Essadki, "Comparative study of active disturbance rejection control with RST control for variable wind speed turbine based on doubly fed induction generator connected to the grid", Int. J. Intell. Eng. Syst., Vol. 13, No. 1, pp. 248-258, 2020.

[5] A. Touati, E. Abdelmounim, M. Aboulfatah, R. 
Majdoul, and A. Moutabir, "Design of an Mppt based on the torque estimator for variable speed turbines", In: Proc. 2015 Int. Conf. Electr. Inf. Technol. ICEIT 2015, No. 1, pp. 166-171, 2015.

[6] A. Touati, E. Abdelmounim, M. Aboulfatah, A. Moutabir, and R. Majdoul, "Improved strategy of an MPPT based on the torque estimator for variable speed turbines", Int. Rev. Model. Simulations, Vol. 8, No. 6, pp. 620-631, 2015.

[7] I. Yasmine, E. B. Chakib, and B. Badre, "Improved Performance of DFIG-generators for Wind Turbines", Int. J. Pow. Electro. Driv. Syst., Vol. 9, No. 4, pp. 1875-1890, 2018.

[8] W. Srirattanawichaikul, S. Premrudeepreechacharn, and Y. Kumsuwan, "A comparative study of vector control strategies for rotor-side converter of DFIG wind energy systems", In: Proc. of 2016 13th Int. Conf. Electr. Eng., 2016.

[9] R. Pena, J. C. Clare, and G. M. Asher, "Doubly fed induction generator using back-to-back PWM converters and its application to variablespeed wind-energy generation", IEE Proc. Electr. Power Appl., Vol. 143, No. 3, pp. 231-241, 1996.

[10] J. Morren and S. W. H. de Haan, "Ridethrough of wind turbines with doubly-fed induction generator during a Voltage dip", IEEE Trans. Energy Convers., Vol. 20, No. 2, pp. 435-441, 2005.

[11] N. H. Saad, A. A. Sattar, and A. E. A. M. Mansour, "Low Voltage ride through of doubly-fed induction generator connected to the grid using sliding mode control strategy", Renew. Energy, Vol. 80, pp. 583-594, 2015.

[12] O. Adekanle, M. Guisser, E. Abdelmounim, and M. Aboulfatah, "Adaptive backstepping control of grid-connected doubly-fed induction generator during grid Voltage dip", In: Proc. of 2017 Int. Conf. Electr. Inf. Technol, Vol. 2018Janua, pp. 1-6, 2018.

[13] O. S. Adekanle, M. Guisser, E. Abdelmounim, and M. Aboulfatah, "Nonlinear controller with rotor crowbar and DC-chopper fault ride through technique for grid-connected doublyfed induction generator", Int. Rev. Autom. Control, Vol. 11, No. 6, pp. 281-292, 2018.

[14] F. Mwasilu, J. J. Justo, K. S. Ro, and J. W. Jung, "Improvement of dynamic performance of doubly fed induction generator-based wind turbine power system under an unbalanced grid Voltage condition", IET Renew. Power Gener., Vol. 6, No. 6, pp. 424-434, 2012.

[15] J. J. Justo, F. Mwasilu, and J. W. Jung, "Doubly-fed induction generator based wind turbines: A comprehensive review of fault ridethrough strategies", Renew. Sustain. Energy Rev., Vol. 45, pp. 447-467, 2015.

[16] I. Erlich, H. Wrede, and C. Feltes, "Dynamic behaviour of DFIG-based wind turbines during grid faults", IEEJ Trans. Ind. Appl., Vol. 128, No. 4, pp. 1195-1200, 2008.

[17] Y. Shen, B. Zhang, T. Cui, J. Zuo, F. Shen, and D. Ke, "Novel Control of DFIG with ESD to Improve LVRT Capability and to Perform Voltage Support during Grid Faults", In: Proc. of 1st IEEE Int. Conf. Energy Internet, pp. 136141, 2017.

[18] S. Q. Bu, W. Du, H. F. Wang, and S. Gao, "Power angle control of grid-connected doubly fed induction generator wind turbines for fault ride-through", IET Renew. Power Gener., Vol. 7, No. 1, pp. 18-27, 2013.

[19] J. Yang, J. E. Fletcher, and J. O'Reilly, "A series-dynamic-resistor-based converter protection scheme for doubly-fed induction generator during various fault conditions", IEEE Trans. Energy Convers., Vol. 25, No. 2, pp. 422-432, 2010.

[20] C. Zhang, S. V. Gutierrez, F. Plestan, and J. De León-Morales, "Adaptive super-twisting control of floating wind turbines with collective blade pitch control", IFAC-PapersOnLine, Vol. 52, No. 4, pp. 117-122, 2019.

\section{Appendix}

$\begin{array}{ll}V_{p c c} & \text { Common coupling point voltage } \\ v_{g} & \text { Network voltage } \\ V_{d c} & \text { DC-link voltage } \\ I G B T & \text { Insulated-Gate Bipolar Transistor } \\ Y & \text { Star coupling } \\ D & \text { Delta coupling } \\ P_{f}, Q_{f} & \text { Filter Active and Reactive Power } \\ v_{d s}, v_{q s} & \text { Direct and quadrature stator voltage } \\ v_{d r}, v_{q r} & \text { Direct and quadrature rotor voltage } \\ i_{d s}, i_{q s} & \text { Direct and quadrature stator current } \\ i_{d r}, i_{q r} & \text { Direct and quadrature rotor current } \\ \varphi_{d s}, \varphi_{q s} & \text { Stator flux linkage } \\ \varphi_{d r}, \varphi_{q r} & \text { Roror flux linkage } \\ R_{s}, R_{r} & \text { Stator and rotor resistance } \\ \omega_{s}, \omega_{r} & \text { Slip and stator angular velocity } \\ p & \text { Number of pairs of machine poles } \\ L_{s}, L_{r} & \text { Stator and rotor self inductance } \\ M & \text { Mutual inductance } \\ P_{s}, Q_{s} & \text { Stator Active and Reactive Power } \\ P_{r}, Q_{r} & \text { Rotor Active and Reactive Power } \\ T_{e m} & \text { Electromagnetic torque } \\ R_{f}, L_{f} & \text { Resistance end self of filter }\end{array}$


Received: February 22, 2021. Revised: May 27, 2021.

$\lambda_{i}, \beta_{i}, \gamma_{i} \quad$ Controller constants of RSC

$L \quad$ Observer gain

$\sigma_{i}, \delta_{i}, \rho_{i} \quad$ Controller constants of NSC 